\title{
Comparación de las relaciones Ejecutivo-Legislativo en Japón y México (2003-2004)
}

$\Lambda_{\text {a lo largo de los }}^{\text {ntecedentes }}$

México se han creado condiciones similares respecto a la relación entre los poderes Ejecutivo-Legislativo, como consecuencia casi directa de la preeminencia en México de un sistema de partido hegemónico (puesto que estaba diseñado para que la competencia no amenazara al partido y éste dominara ambos poderes) que dio como resultado un gobierno indiviso hasta 1997, y de una caracterización mayor de un sistema de partido dominante en Japón (sistema en el cual la competencia sí tenía viabilidad para ganar, aunque solo un partido dominara Japón en todos sus rubros políticos durante treinta y ocho años continuos), siendo plenamente constante. Por ello, aunque en Japón se hayan asimilado en mayor proporción las medidas reales de competitividad en el sistema político por su característica parlamentaria, el partido dominante retomó de nuevo el poder después de haberlo perdido en 1993.

En México por el contrario, con características de sistema presidencial, todavía sorprenden las nuevas condiciones que se generaron en este rubro, a raíz de que el partido del Presidente perdiera la mayoría absoluta en la Cámara de Diputados en 1997, y la misma Presidencia en el año $2000 .{ }^{1}$ Es decir, el partido dominante cayó y la nueva distribución del poder cambió la manera en la que se desarrollan las actuales relaciones EjecutivoLegislativo en comparación a las anteriores, cuando un solo partido controlaba ambos rubros. Factor que también ha ocurrido en Japón, a pesar de tener un sistema parlamentario.
Cabe mencionar que aunque estas relaciones puedan ser cualitativamente diferentes por las características particulares o generales de cada sistema, la preeminencia en el gobierno de un partido dominante en los dos países, creó condiciones políticas similares respecto a las relaciones entres los poderes de la Unión aquí analizados. Con este antecedente se pretende analizar la conformación de sus nuevos mapas políticos, después de que el partido dominante en ambos casos perdiera el control sobre las dos cámaras de sus respectivos congresos.

Por ello, aunque sin duda alguna podría resultar paradójico comparar las relaciones Ejecutivo-Legislativo de un sistema presidencial (el caso de México) con las de uno parlamentario (caso Japonés) por el contexto político cualitativamente diferente, en este trabajo se estudiará cada sistema tomando en cuenta las administraciones actuales, para determinar precisamente sus similitudes y diferencias. El objetivo planteado surge a partir del interés por analizar la manera en la que tanto en una monarquía parlamentaria como en un presidencialismo, influyó el dominio de un solo partido durante décadas para que las fuerzas políticas actuaran en consecuencia, en torno a la diferenciación de las funciones del Ejecutivo con las del Legislativo.

Respecto al Poder Legislativo, se pretende conocer la composición de los congresos federales de Japón y de México; la forma en cómo se distribuyen el poder en las cámaras los partidos políticos más importantes en ambos países; la duración de los legisladores en cada Cámara, así como analizar brevemente el desarrollo del proceso legislativo en el Congreso de cada país.

* Lic. en Relaciones Internacionales. 
Respecto al Poder Ejecutivo, se pretende estudiar cómo las composiciones de sus respectivos Congresos le cierran o abren la puerta a sus propuestas de gobierno, y ver también cómo influye la temporalidad de los períodos presidenciales y de los primeros ministros (en el caso de Japón), en la relación del Ejecutivo con el Legislativo.

\section{PLD y PRI: los partidos del sistema parlamentario y del presidencial}

En Japón el Partido Liberal Democrático (PLD) se mantuvo durante treinta y ocho años de forma ininterrumpida en el poder desde una perspectiva democrática-competitiva. ${ }^{2}$ Tanto el Legislativo como el Ejecutivo han tenido un importante desarrollo como instituciones políticas guiadas por un mismo partido, debido a la fortaleza que ha mostrado el PLD en ese país. Esta constancia propició que cada primer ministro en turno tuviera mayoría en la Dieta (Congreso japonés) en ambas cámaras durante el tiempo antes mencionado, y no se viera en la necesidad de negociar con la oposición los proyectos e iniciativas de ley que se debían implementar para evitar la parálisis gubernamental, sino que, por el contrario, esas negociaciones eran sustituidas por las diferencias y discrepancias que surgían al interior del partido. De acuerdo con José Antonio Crespo, "la ausencia de alternancia partidista en el sistema de partidos japonés fue compensada por la competencia de las fracciones políticas en el interior del propio PLD". ${ }^{3}$

En un sistema parlamentario, la soberanía del pueblo radica principalmente en el Parlamento, teniendo al primer ministro solo como guía de su gobierno. Por eso, el PLD se dio a la tarea de dominar no sólo el Ejecutivo, sino también el Legislativo en su totalidad, para garantizar que el poder sustentado en ambos caminara bajo su línea política. Y es que en Japón se elige como primer ministro al presidente del partido que tenga mayoría en el Congreso.
En México se ha dado un caso similar aunque no exactamente igual. Según María Amparo Casar, el sistema político mexicano (presidencialista) se caracterizó por ser de un partido hegemónico desde 1917. Mediante este engranaje, se le concedió al jefe del Ejecutivo penetrar en las instituciones políticas, permitiéndole decidir sobre su composición y su comportamiento. ${ }^{4}$ Mediante el control del reparto de cargos y la continuidad de las carreras políticas, el Ejecutivo sentó las condiciones para que el Congreso renunciara a sus atribuciones. Por lo tanto, "una vez controlado el punto de la representación, los otros dos - hacer leyes y contrarrestar el poder presidencial- fueron voluntariamente abandonados". ${ }^{5}$

Afortunada aunque lentamente, en México se ha evolucionado respecto al equilibrio de poderes, puesto que a partir de las reformas constitucionales en materia electoral de la década de los noventa, a los partidos políticos se les han brindado condiciones de igualdad en el terreno competitivo. A partir de 1988, la Cámara de Diputados se convirtió en el elemento clave de la maquinaria constitucional que encendió el motor del cambio democrático, al perder el Partido Revolucionario Institucional (PRI) la mayoría calificada, e incrementar con ello el poder negociador de la oposición en los procesos de reforma constitucional. En las elecciones de 1997 surgió el primer gobierno dividido de la historia en México, cuando el PRI perdió hasta la mayoría absoluta en la Cámara de Diputados. ${ }^{6}$

\section{Diferencias y similitudes de las estructuras políticas}

En esta sección se muestran la composición actual de los congresos y las perspectivas de gobierno que tienen Junichiro Koizumi y Vicente Fox para gobernar, en un contexto en el que sus respectivos partidos ya no dominan las dos cámaras de sus Congresos.

El Congreso de Japón (Dieta o Kokkai) está compuesto por una Cámara de Representantes y una de Consejeros. La primera representa proporcionalmente a la población del 
país y cuenta con 480 representantes desde febrero de 2000 (año en que fuera reducida en veinte escaños), los cuales se eligen por un período de cuatro años, que puede ser acortado en razón de la disolución de la Dieta ${ }^{7} .300$ representantes son electos por mayoría relativa o votación directa y los otros 180 son electos por representación proporcional. La Cámara de Consejeros se compone de 252 personas, las cuales son electas cada seis años y se renueva por mitades cada tres años: 152 consejeros son electos con base en circunscripciones localizadas en cuarenta y siete prefecturas; los otros 100 son integrados por representación proporcional con base en una circunscripción que abarca la totalidad del territorio nacional. Cabe destacar que esta Cámara no está sujeta a disolución, por lo que los consejeros deben terminar su período, a diferencia de la Cámara de los Representantes. ${ }^{8}$

Un proyecto de ley puede ser presentado por un miembro de la Dieta o por el gabinete. Los proyectos de ley presentados son remitidos a un comité apropiado para su deliberación. Un proyecto aprobado por una Cámara es enviado a la otra, y el proyecto solo se convierte en ley si es aprobado en ambas cámaras. Esto es similar a lo que sucede en México con el proceso legislativo. Una característica propia de Japón es que la mayoría de los proyectos de ley, son generalmente iniciados en la Cámara de Representantes, la otra Cámara generalmente se convierte en revisora (o mejor conocida como el lugar para decidir el destino del proyecto). Aunque cabe aclarar que no siempre. ${ }^{9}$

El Congreso mexicano se compone también de dos cámaras legislativas: una Cámara de Diputados y la otra de Senadores. La primera cuenta con un total de 500 diputados, de los cuales 300 se eligen por mayoría relativa y 200 por representación proporcional. Cada diputado representa un promedio de 200000 habitantes. Su período de duración es de tres años y no pueden ser reelectos inmediatamente después de que termina su período de tres años como legisladores. ${ }^{10}$ La Cámara de Senadores se compone de un total de 128 personas, de las cuales a partir de 1993, sesenta y cuatro se eligen por mayoría relativa, treinta y dos por primera minoría, y otro tanto igual por representación proporcional. ${ }^{11}$

Ambas cámaras se organizan para votar las iniciativas y propuestas de ley en grupos parlamentarios formados por un mínimo de cinco legisladores de un partido político. Cada grupo tiene un coordinador. A los coordinadores de los grupos parlamentarios (o de su partido) les corresponde realizar las tareas de coordinación con la mesa directiva. Las comisiones y comités de las cámaras forman parte de una Junta de Coordinación Política para mejorar las labores bicamerales. ${ }^{12}$

Volviendo con el sistema político japonés, éste es definido como una monarquía parlamentaria pues Japón, a diferencia de cualquier sistema presidencial en donde la función de jefe de Estado y Gobierno lo ejercen la misma persona, tiene un sistema parlamentario en donde existe una clara división entre ambos. El jefe de Estado (emperador Akihito, desde el 7 de enero de 1989) representa a la nación en cualquier ceremonia diplomática y es el símbolo de unidad japonesa; mientras que el jefe de Gobierno (primer ministro, Junichiro Koizumi, desde el 24 de abril de 2001) se encarga de las políticas públicas y de dirigir la burocracia. La elección del emperador es de forma hereditaria y la del primer ministro es por medio del voto indirecto del pueblo. Es decir, los ciudadanos primero eligen a los miembros del Parlamento y éstos a su vez al primer ministro, quien en la mayoría de los casos es el líder del partido de mayoría en el Parlamento o Dieta, o de la coalición mayoritaria, cuando no hay un partido con mayoría absoluta (entiéndase mayoría absoluta al 50\% $+1)^{13}$

Este sistema también es considerado monarquía parlamentaria, porque el Parlamento (la Dieta) puede destituir al primer ministro; éste a su vez depende de los resultados electorales y de su desempeño en el gobierno. También puede sugerir al jefe de Estado la destitución del Parlamento. ${ }^{14}$ En el caso espe- 
cífico de Japón, sólo la Cámara de Representantes puede ser disuelta. Por eso se dice que aunque el Poder Legislativo limita las decisiones del Ejecutivo, así como su estancia en el poder, no obstaculiza la aplicación de las políticas públicas gracias a una burocracia fuerte.

En Japón se han dado ya disoluciones de Parlamento y de primer ministro, y las más frecuentes se deben a la desconfianza surgida entre ambos poderes (Ejecutivo-Legislativo) relacionada con los actos de corrupción del primer ministro o gente muy cercana a él. Aquí es donde se retoma lo que al inicio se mencionó: las mismas facciones al interior del PLD se han encargado de verificar en la Dieta que el líder de la facción en el poder no actúe con alevosía.

La composición actual de la Dieta en la Cámara de Representantes está compuesta de 480 miembros. Para que un partido pueda tener mayoría absoluta debe contar con 241 curules; en las elecciones de enero de 2002, el PLD superó ese número sólo por un escaño más, ya que conquistó 242 . Pero no corrió con igual suerte en la Cámara de Consejeros, ya que consiguió 115, y los que necesitaba obtener eran 127 escaños. $^{15}$

La composición de ambas cámaras en la última elección quedó de la siguiente manera: en la Cámara de Representantes el PLD consiguió 242 escaños; el Partido Demócrata Japonés (PDJ), 126; el Komeito, treinta y uno; el Partido Liberal, veintidós; el Partido Comunista Japonés (PCJ), veinte; el resto de los partidos, treinta y nueve. Con estos números podemos darnos cuenta que aunque cada vez es menor la ventaja del PLD respecto a los demás partidos, aún sigue manteniendo la mayoría absoluta en esta Cámara, que es en la que nunca ha perdido. Aunque cada vez se acorta más la distancia entre el PLD y sus opositores, este partido puede en esa cámara por si solo aprobar un proyecto de ley para el que no necesite la mayoría calificada (66\% de los miembros). Respecto a la Cámara de Consejeros, la nueva composición tras las elecciones de enero de 2002 quedó de la siguiente manera: el PLD consiguió 115 escaños; el PDJ, sesenta; el Komeito, veinticuatro; el PCJ, veinte; el PSD, ocho; el Partido Liberal, ocho; independientes seis, otros seis. ${ }^{16}$ Es en esta cámara donde el PLD (después de su derrota en 1993 y en 1998) no se ha vuelto a recuperar y donde además necesita alguna alianza para sacar adelante los proyectos que requiera.

Respecto a México, la conformación de las cámaras es más plural que antaño, puesto que ningún partido cuenta con la mayoría absoluta. En la historia, el Senado había tenido hasta 1993 una mayoría abrumadoramente priísta. A continuación se presenta el número de escaños que adquirió cada partido en ambas cámaras, en las elecciones celebradas en 2000 y en 2003. La Cámara de Diputados está formada por 500 integrantes. Para que un partido político pueda tener la mayoría absoluta, por lo menos debe contar con 251 escaños, pero en México, ningún partido estuvo cerca siquiera de conseguirlo en ninguna de las elecciones, ya que el más cercano fue el PRI con 211; el PAN le siguió con 206 y el PRD con cincuenta, en las elecciones de $2000 .{ }^{17} \mathrm{En}$ los comicios de 2003 para la Cámara de Diputados, el PRI consiguió una mayoría simple, y aunque aumentó su número de escaños a 223 , estuvo lejos de alcanzar la mayoría absoluta. El partido del actual Presidente (PAN) disminuyó su número de escaños en cincuenta y dos si se compara con la elección anterior, al solo conseguir 154, y por ese motivo fue considerado como el perdedor de estas elecciones. El PRD por su parte aumentó su 
número de curules en cuarenta y seis, al conseguir noventa y seis asientos. El PVEM se quedó con sus mismos diecisiete, el Pт y el Partido Convergencia consiguieron cinco cada uno. ${ }^{18}$ Como puede verse, ni si quiera una alianza con los partidos pequeños le podría ser favorable al partido del Presidente.

En la Cámara de Senadores que está compuesta por 128 miembros, para que un partido cuente con la mayoría absoluta debe tener por lo menos 65 escaños, y como puede observarse en los datos siguientes, el PRI se quedó cerca de conseguirlos en las elecciones de 2000, al ganar solo sesenta; el PAN consiguió cuarenta y seis; el PRD, dieciséis; y entre todos los demás se repartieron los otros seis restantes. ${ }^{19}$ Por lo tanto, como señala Woldenberg, ${ }^{20}$ puede decirse que el país que gobierna el presidente Vicente Fox ya no es el de un tronco mayoritario, sino el de mayorías que se construyen. La suma de los votos y de los legisladores de la oposición es una mayoría absoluta sobre el gobierno triunfante. Con ello, México entró de lleno en una etapa política cuyo objetivo y marco esencial es el de la construcción de alianzas legislativas para gobernar al país.

Mientras que a Junichiro Koizumi su partido le puede aprobar un proyecto en la Cámara Baja (y que en la Cámara Alta tiene que negociar con un partido fuerte de oposición para que sus propuestas sean aprobadas), en México debe tomarse en cuenta que "Fox de manera obligatoria debe ir en busca del PRI o del PRD, en ambas cámaras", y que además estos dos partidos de oposición son muy fuertes y de ideologías distintas. ${ }^{21}$ El Poder Ejecutivo en México tiene frente a sí a legisladores de oposición, que por el sistema de selección partidaria (la representación proporcional) casi la mitad de ellos, si quieren continuar con sus carreras políticas, deben caminar según la ideología de sus partidos a costa de los intereses de sus electores.

\section{Conclusiones}

Se puede observar que el PLD sigue siendo un partido fuerte debido al hecho de que todavía posee la mayoría absoluta en la Cámara Baja, que es considerada la de más peso en Japón por ser la encargada del presupuesto, de proponer al primer ministro, y de ser generalmente la cámara de origen en la mayoría de los proyectos. Por ese hecho, aunque Junichiro Koizumi tenga el riesgo de ser destituido antes de que su período concluya y que su permanencia en el poder dependa de sus resultados, su partido por sí solo le puede aprobar un proyecto en la Cámara Baja, y únicamente tiene que negociar con un partido fuerte de oposición en la Cámara Alta para que sus propuestas sean aprobadas. Esto se debe también a las características de su sistema parlamentario.

El caso mexicano es distinto puesto que como lo subraya José Woldenberg, ${ }^{22}$ las condiciones generadas en el juego parlamentario del México actual se caracterizan en dos condiciones: primero, ningún partido tiene mayoría absoluta en el Congreso; segunda, ninguna de las coaliciones electorales tiene mayoría calificada. Por lo tanto, están las condiciones dadas para que se desarrolle la democracia en toda la extensión de la palabra. Una vez planteado este engranaje político, Hurtado ${ }^{23}$ considera que "la gran interrogante es si ahora se generará un auténtico equilibrio entre ambos poderes, o se pasará del anterior sometimiento del Legislativo al Ejecutivo a la subordinación de la Presidencia ante el Congreso, como ocurrió en la época descrita por Emilio Rabasa, cuando se determinó la constitución de 1857”.

El lado positivo de este nuevo orden político en México es que ya no predominará (al menos en el corto plazo) la figura presidencial autoritaria ni el dogmatismo político de épocas pasadas, al ser ahora tomadas en cuenta las minorías. Pero por el lado negativo, se puede decir que si los partidos políticos que no están en el poder y que tampoco tienen mayorías en el Congreso obstruyen la labor del Ejecutivo, se corre el riesgo de llegar a una parálisis gubernamental.

Después de las últimas elecciones legislativas del 6 de julio de 2003, todos los parti- 
dos aumentaron su número de curules en la Cámara de Diputados, menos el partido del gobierno. Además, de acuerdo con Carlos Elizondo, Elías Cordoba y Flores Andrade, ni aunque el PRI haya obtenido una mayoría simple en la nueva conformación partidista, hubo cambios significativos en la Cámara. ${ }^{24}$

Lo único preocupante para Flores Andrade ${ }^{25}$ es que después de los resultados de estos últimos comicios, el Ejecutivo quedó más debilitado y con menor fuerza que nunca para sacar adelante las reformas estructurales que tanto ha promovido. Más preocupante para el Ejecutivo es que el Legislativo, con la conformación de esta y la anterior Legislatura, se ha convertido en un factor real de poder y en un contrapeso verdadero (especialmente en el período del presidente Vicente Fox), y parece no estar del todo dispuesto a sacar del impasse la relación tensa en la que se encuentran estos poderes desde el año 2000.

Finalmente, a diferencia de Japón, con la instalada democracia en México, se presenta un nuevo fenómeno que era poco común en años anteriores. Empiezan las carreras presidenciales al interior de cada partido para el año 2006. Algunos de los supuestos precandidatos son diputados muy influyentes recientemente electos y otros pocos secretarios de Estado que no piensan concluir su trabajo para enfocarse al trabajo de su candidatura. Por ello se vislumbra un panorama gris y oscuro en la relación Ejecutivo-Legislativo, puesto que mientras el PRI lucha por el poder político, en el PAN se podría seguir ahondando más el distanciamiento que se gestó con el Presidente en la Legislatura pasada, y por ende, ocuparse más de hacer publicidad y dejar parado al país. ¡Bueno, nadie dijo que la democracia fuera perfecta y en consecuencia útil para todo!

\section{Notas}

1 Lujambio, Francisco. El poder compartido. Un ensayo sobre democratización mexicana. México: Ed. Océano, 2000, pp. 33-41.

2 Crespo, José Antonio. "Hacia un nuevo modelo de dominación política. Un enfoque comparativo entre Japón y México". Documento de trabajo (revista núm. 27), CIDE, AC., p. 2.

3 Crespo, José Antonio. "El Partido Liberal Democrático en Japón: el demonio conservador". Documento de trabajo (revista núm. 13), CIDE, AC. pág. 8.

4 Casar, María Amparo. "Las bases político institucionales del poder presidencial en México" revista Política y Gobierno, vol. III, núm. 1, CIDE, 1996, pp. 83-85.

5 Casar, María Amparo. "Las relaciones entre el Poder Ejecutivo y el Legislativo", revista Política y Gobierno, vol. I, México, 1999, pp. 121-122.

6 Lujambio, op. cit., p. 41.

7 Cámara de los Representantes de Japón. En sitio Web oficial en inglés: http://www.shugiin.go.jp/index.nsf/html/ index_e_guide.htm. 15 y 16, 06, 2003.

8 World Language, en http://www.worldlanguage.com/ Spanish/Countries/Japan.htm

9 Cámara de Consejeros de Japón. En sitio Web oficial en inglés: http://www.sangiin.go.jp/eng/guide/index.htm. 18-20, 06, 2003.

10 Cámara de Diputados. En www.camaradediputados.gob.mx, 15, 11, 2002

11 Cámara de Senadores. En www.senado.gob.mx, 15, 11, 2002

12 Cámara de Diputados, op. cit.

13 Fundación Japón-México. En http://www.fjmex.org/ mexico/elpatio/vol9/vol09_3.htm. 18, 11, 2002.

14 Hurtado, Javier. Sistemas de Gobierno y Democracia. Cuadernos de divulgación de la cultura democrática, núm. 19, México: IFE, 2001, p. 14.

15 World Language, op. cit.

16 Idem.

17 Woldenberg, José. La construcción de la democracia, Plaza \& Janes editores, 2002. p. 15.

18 Instituto Federal Electoral de México. En sitio oficial: www.ife.org.mx. 10, 09, 2003, y 12, 09, 2003.

19 Cámara de Senadores. En: http://www.senado.gob.mx/ gruposparlamentarios

20 Woldenberg, op. cit., p. 52.

21 Ibid., p. 51.

22 Idem.

23 Hurtado, Javier. "Relación Presidencia-Congreso en el proceso legislativo del México de nuestros días". Ponencia presentada en la Universidad Nacional Autónoma de México, septiembre de 2002.

24 Aguilar, César. "La Cámara de Diputados será factor real de poder", revista Vértigo, año III, núm. 121, julio, 2003, pp. 34-37.

25 Idem. 